\title{
Academic Comparison of Athletes and Non-Athletes in a Rural High School
}

Holt E Zaugg

holt_zaugg@byu.edu

Follow this and additional works at: https://scholarsarchive.byu.edu/facpub

Part of the Educational Assessment, Evaluation, and Research Commons, and the Sports Sciences Commons

\section{Original Publication Citation}

National Association of Secondary School Principals. NASSP Bulletin, 82, 63-72

\section{BYU ScholarsArchive Citation}

Zaugg, Holt E, "Academic Comparison of Athletes and Non-Athletes in a Rural High School" (1998).

Faculty Publications. 1472.

https://scholarsarchive.byu.edu/facpub/1472 


\section{Academic Comparison of Athletes and Non-Athletes in a Rural High School}

Abstract: This study compares academic performance, behavior, and commitment of basketball and volleyball athletes and non-athletes in a rural Canadian high school. It compares mid-term and final grades in each school discipline; visits to an administrator for disciplinary visits; and demerit points for improper behavior; and estimates the mean weekly time commitment for athletes in each sport.

Many believe that athletics in school is contrary to values that promote learning and academic performance. Carlson (1993) describes an urban high school noted for producing civic, educational, and business leaders. As the school rose to prominence in athletics, it declined in academic performance. Instead of graduating and boasting of strong community and business leaders, the school now boasts of students who have been drafted and play in professional sports. Other studies found conflicting results. Haynes (1990) cites a study of 58,000 high school juniors and seniors that found athletes were generally better students except for the two "big" sports, football and basketball.

Maloney and McCormick (1993) support the finding that athletes in revenue sports do not, on average, perform as well in the classroom as their non-athlete peers. Athletes in the non-revenue sports had no difference in grades with non-athletes. Hood, Craig, and Ferguson (1992) reported that athletes in the revenue-producing sports entered university with lower admissions indices compared with other freshmen. These studies inferred that students in high-pressure or high-profile sports tend to focus more on their sport than on their academic performance.

Other studies supported athletics, not for academics, but for a wide range of ways that athletics enhances education. They claimed that athletics contributed to socialization in schools (Gerdy, 1992); teamwork, sportsmanship, and citizenship skills (Harper, 1986); leadership skills and satisfaction with the college experience (Hood, Craig, and Ferguson, 1992). Athletic participation raised educational aspirations, selfconcept, and GPAs (Soltz, 1986). Athletics also contributed to students' sense of belonging or status within society and the school (Goldberg and Chandler, 1992). It developed personal and moral character while promoting leadership, cooperation, coping strategies, risk taking, and achievement behavior (Thompson, 1986). Students involved in athletics have considerably fewer discipline problems and school suspensions, and non-school related drug, alcohol, and tobacco abuse, and serious offenses with the law (Rombokas, et al., 1995).

Institutions with strong academic and athletic programs identified and emphasized standards of excellence students must demonstrate in behavior and academics to be able to participate in athletics. Many supported a minimum grade, GPA, or behavior standards to allow students to participate at all levels of school sport (Ruffin, 1986; Thompson, 1986; McMillen, 1991; Morton et al., 1993; American Sports Institute, 1996). Many coaches who run successful athletic programs demand high academic standards from their athletes. This includes selecting hard-working individuals, monitoring academic progress, cooperating with the academic faculty, instilling academic pride, and 
demanding more than the minimum (Scherer, 1990; Carlson, 1993). The higher standards and expectations improved the rate of graduation and the success of the individual after graduation.

The National Colleges Athletic Association (NCAA) now requires a minimum standard of academic excellence for all athletes. This began with Proposition 16 and continued with Proposition 48, which raised the academic standards for NCAA athletes (Thompson, 1986; Owings, McMillen, and Daniel, 1995). Many states and provinces mandated or encouraged minimum academic standards for participation in cocurricular activities. This included limiting years of participation to standards of behavior and academic performance.

Morton (1993) described the effects of standards on three groups of students. The first group of students performed well with or without standards. The standards motivated the second group of students to achieve their potential and succeed academically. The third group of students performed poorly with or without standards. Morton reported that standards helped students in the second group to enter college better prepared, to graduate, to balance priorities, and to not be manipulated by the demands of their sport (Whitner and Myers, 1986). Standards helped the athletes learn values and make judgments that led to their success.

If academic and behavior standards are to work, clear indicators should be present. Athletes' grades must equal or exceed non-athletes' grades. Athletes must demonstrate better behavior than non-athletes. Time commitments of athletes must allow athletes to participate in sports, but also concentrate on academics and other aspects of their education. The demands of the sport must approximate that of another academic course.

The present study investigated each of those aspects in a rural Canadian high school. The study hypothesized the following:

1. There will be no significant difference between the athlete and non-athlete mid-term or final grades in each discipline.

2. Athletes will have significantly fewer behavioral problems (i.e., disciplinary visits, demerit points, absenteeism) than non-athletes.

3. Athlete's mean weekly time commitment for practice and games equals the time commitment for an academic course.

\section{Method}

Participants. The subjects included 134 high school students (52 athletes and 82 non-athletes) in the Magrath Junior/Senior High School during the 1996-97 school year. All subjects were from a small town or rural farm environment and of primarily European descent. All subjects were between the ages of 15 and 19 and in grades 10-12. Among the athletes there were 24 males and 28 females on the basketball and volleyball teams. Among the non-athletes there were 42 males and 40 females.

Procedure. The study compared the mean mid-term and final grades of athlete and non-athlete students by discipline (i.e., math, social studies, English, and science) and the mean grades of all other courses combined. Student scores (mid-term and final grade) for each course were used. The only exception was Mathematics 31, which was a yearlong course instead of a semester course. In this case first report card and mid-term 
grades were used respectively as mid-term and final grades.

The study compared school behaviors of athlete and non-athlete students by the number of times students were sent to the office for discipline, and demerit points received for inappropriate behavior and absenteeism. Fewer demerit points were given for lesser offenses (i.e., repeated tardiness) and more demerit points were given for more serious offenses (i.e., fighting). Thus, a student with fewer disciplinary visits but a higher demerit point score indicated more serious behavior problems.

\section{Table 1}

Courses and Students Enrolled in Each Discipline

\begin{tabular}{llc} 
Discipline & Courses in Discipline & Total Students \\
\hline English & English, 10, 20, 23, and 30 & 21 \\
Mathematics & Math 10, 20, 23, 30 and 31 & 36 \\
Sciences & Biology 20 and 30 & 38 \\
& Chemistry 20 and 30 & \\
& Physics 30 & \\
& Science 10 and 14 & \\
Social Studies & Social Studies 10, 13, 20, 30, and 33 & 30 \\
Other Courses & Accounting 10 and 20 & 83 \\
& Career and Life Management 20 & \\
& Clothing and Textiles 20 & \\
& Computers 10 and 20 & \\
& Drivers' Education 10 \\
& Foods 10 \\
& French 13, 20 and 30 & \\
& Industrial Education 20 and 30 \\
& Music 10, 20 and 30 \\
& Physical Education 10 and 20 \\
& Psychology 20 \\
\hline
\end{tabular}

Finally, the study estimated time commitments student athletes made to attend games, matches, tournaments, and practices. This measure was estimated by team because game and match time varied a great deal between sports and between varsity and junior varsity teams.

After students were selected for basketball and volleyball teams, the athlete and nonathlete groups were chosen. All male and female students who played basketball or volleyball (varsity or junior varsity) for the 1996-97 season were assigned to athlete student groups.

Subjects for the non-athlete group were chosen in the following manner: Course lists for each athlete were created. Non-athlete students were randomly selected to match the course and sex of each athlete student. For example, if a male athlete took Math 33, then a male non-athlete was chosen at random from all Math 33 male non-athlete students. Once chosen, a non-athlete would be paired in as many courses with a same- 
sex athlete as possible. In two courses athlete students could not be paired by sex with non-athletes. In these cases two male non-athletes were randomly chosen instead of female non-athletes.

Several students in the school were multi-sport athletes (i.e., volleyball and cheerleading, volleyball and hockey, or rodeo and basketball). All multi-sport athletes were included in the athlete group. Students who participated only in cheerleading, rodeo, or hockey were eliminated from the athlete and non-athlete groups. Of the 52 students in the athlete group 17 students played both volleyball and basketball. All mid-term and final marks were collected and recorded in a double blind manner (collected and recorded by an independent person) to protect student privacy. Courses that required a provincial departmental exam included the provincial exam as part of the course's final grade.

Student behavior records were collected in a double blind manner for the first semester of school (September 1 - January 30). For each student, the total number of disciplinary visits, total number of demerit points, and total number of class periods absent were recorded. Mean scores and percent of total for each category (disciplinary visits, demerit points, absenteeism) were recorded.

The total number of matches (volleyball), and games (basketball) in league play and tournament play for each team was recorded. Time to play each match, game, or tournament as well as practices was estimated. Travel time and waiting time were not included in the estimates.

The study was only conducted during the first semester of school when each sport took at least three of the five months in the semester. As a result, the entire volleyball season was completed (including zone and provincial play), but only 60 percent of the basketball season was completed.

\section{Analysis}

Paired t-tests comparing the mean scores of athlete and non-athlete groups on midterm grades, final grades, disciplinary visits, demerit points, and classes absent were conducted to determine whether the differences in the mean scores of the two groups were significantly different $(\mathrm{p}<.05)$. No analysis was conducted on the playing and practice times.

\section{Results}

Table 2 shows the mean scores and standard deviations by group for each discipline (i.e., math, English, etc.) mid-term grade. No significant difference between the athlete and non-athlete groups for any of the disciplines was found, except for the sciences, where the athlete group was significantly higher than the non-athlete group $(\mathrm{p}<.05)$.

Table 3 shows the mean scores and standard deviations by group for each discipline final grade. No significant difference between the athlete and non-athlete group for any of the disciplines was found, except for the sciences and "all other courses combined" where the athlete group was significantly higher than the non-athlete group $(\mathrm{p}<.05)$. 
Table 2.

Mean Scores and Standard Deviations for Athlete and Non-Athlete Groups for Each Discipline Mid-Term Grade

\begin{tabular}{lrrrrr} 
& \multicolumn{3}{c}{ Athlete } & \multicolumn{2}{c}{ Non-Athlete } \\
Discipline & df & Mean & SD & Mean & SD \\
\hline English & 37 & 77.3 & 9.05 & 73.3 & 11.6 \\
Mathematics & 69 & 75.8 & 16.50 & 76.2 & 16.7 \\
Sciences* & 68 & 81.0 & 9.96 & 74.4 & 13.2 \\
Social Studies & 54 & 78.2 & 13.20 & 71.9 & 16.0 \\
Other Courses & 153 & 84.7 & 11.0 & 81.2 & 14.7 \\
\hline
\end{tabular}

$*(\mathrm{p}<.05)$

Table 3.

Mean Scores and Standard Deviations for Athlete and Non-Athlete Groups for Each Discipline Final Grade

\begin{tabular}{lrrrrr} 
& \multicolumn{3}{c}{ Athlete } & \multicolumn{2}{c}{ Non-Athlete } \\
Discipline & df & Mean & SD & Mean & SD \\
\hline English & 39 & 74.6 & 8.14 & 70.3 & 8.82 \\
Mathematics & 69 & 74.5 & 16.30 & 71.5 & 16.80 \\
Sciences* & 73 & 78.7 & 11.10 & 72.4 & 12.20 \\
Social Studies & 54 & 75.3 & 15.30 & 68.4 & 18.50 \\
Other Courses* & 149 & 83.3 & 10.50 & 79.0 & 14.90 \\
\hline
\end{tabular}

$*(\mathrm{p}<.05)$

Table 4 shows the total number of students and the percent of the total group sent to the office by group for disciplinary visits and the mean scores by group for demerit points and classes absent. There was no significant difference between the athlete and nonathlete groups for disciplinary visits or for demerit points, but the athlete group was absent significantly fewer classes than the non-athlete group $(\mathrm{p}<.05)$.

Table 4

Total and Percent of Total Students Sent to the Office for Discipline, Total Disciplinary Visits and Mean Scores for Athlete and Non-Athlete Groups for Demerit Points and Classes Absent

\begin{tabular}{lcc} 
& Athletes & Non-Athletes \\
\hline Number of Students & 52 & 82 \\
Total Student sent to Office for & 8 & 15 \\
Discipline & 15 & 21 \\
Percent of group & 11 & 39 \\
Total Disciplinary Visits & 2.1 & 5.5 \\
Mean Demerit Points & 21.3 & 36.2 \\
Mean Classes Absent* & &
\end{tabular}


Table 5 shows student time commitment to participate in sports in terms of games, practices for each team, and a mean estimated weekly time commitment. All games include a warm-up period. Each varsity league volleyball match (best of five games) was estimated at two hours. Each volleyball tournament match (two games) was estimated at one hour. Each junior varsity league volleyball match (three games) was estimated at one and a half hours. All basketball games were estimated at two hours. Basketball only included games and tournaments until the end of January. Mean estimated time commitments for students ranged from 6.8 to 10.6 hours each week.

\section{Table 5}

Estimates of Student Time Commitment in Terms of Games, Estimated Practice Time, and Total Estimated Time Committed per Week

\begin{tabular}{|c|c|c|c|c|c|c|c|c|}
\hline & \multicolumn{4}{|c|}{ Volleyball } & \multicolumn{4}{|c|}{ Basketball } \\
\hline & \multicolumn{2}{|c|}{ Boys } & \multicolumn{2}{|c|}{ Girls } & \multicolumn{2}{|c|}{ Boys } & \multicolumn{2}{|c|}{ Girls } \\
\hline & JV & Var & JV & Var & JV & Var & JV & Var \\
\hline League Games & 7 & 7 & 9 & 9 & 8 & 8 & 10 & 10 \\
\hline Tournament Games & 0 & 14 & 0 & 7 & 3 & 9 & 3 & 9 \\
\hline Total Games & 7 & 21 & 9 & 16 & 11 & 17 & 13 & 19 \\
\hline Total Time (h) & 10.5 & 42 & 13.5 & 32 & 22 & 34 & 26 & 38 \\
\hline $\begin{array}{l}\text { Mean Weekly Time for Games } \\
\text { (h) }\end{array}$ & .8 & 3.2 & 1.0 & 2.5 & 1.7 & 2.6 & 2.0 & 2.9 \\
\hline Practice h/week & 6 & $6^{* *}$ & 6 & 6 & 8 & 8 & 7 & 6 \\
\hline Total Time/Week & 6.8 & 9.2 & 7.0 & 8.5 & $9.7^{*}$ & $\begin{array}{r}10.6 \\
*\end{array}$ & $8.0^{*}$ & $9.9^{*}$ \\
\hline $\begin{array}{l}\text { JV = junior varsity, Var = Varsit } \\
* \text { Basketball times only include } \\
* * \text { Boys' volleyball practices ext } \\
\text { the boys won zone playoffs and }\end{array}$ & $\begin{array}{l}=\text { hour } \\
\text { percen } \\
\text { ed an } € \\
\text { cticed }\end{array}$ & of $t$ & eas & Cidd & pions & ps. & & \\
\hline
\end{tabular}

\section{Discussion}

The findings support the first hypothesis in 7 of 10 discipline grades. The athlete group was significantly higher than the non-athlete group in the sciences mid-term and final grade, and in the "all other courses" final grade. Although not significant, the athlete group had a practical difference in the social studies mid-term grade (6.3 percent higher) and final grade (6.9 percent higher). This supported earlier findings indicating that participation in athletics is not a detriment to academic progress and may even improve grades (Soltz, 1986).

The findings supported the second hypothesis that athletes have fewer behavioral problems. While both groups had a low percent of individuals who were sent to the office, the athlete group had 6 percent fewer than the non- athlete group. Although not significant, the athlete group had less than half the mean demerit points and less than one-third of the total disciplinary visits of the non-athlete group. The athlete group missed significantly fewer classes. This may be attributed to the school policy that if an athlete misses classes (medical appointments excepted) they do not play or practice with the team that day. Furthermore, students with detentions miss practice and games 
until the detention is served. This is a strong motivation for athletes to exhibit proper conduct. The finding also supports earlier studies that reported lower behavioral problems among athletes (Rombokas, 1995).

The findings support the third hypothesis that mean weekly time commitment for athletics equals that of academic courses. A semestered high school course at Magrath has approximately 6.7 hours of in-class instruction per week, not including homework. The lowest combined time (boy's JV volleyball) equals the in- class instruction time. The highest (boy's varsity basketball) exceeds the in-class instruction time by 4 hours. Grade 12 students have more homework, however, because all 30 and 33-level courses require a provincial government exam. Four hours of studying per week for an academic course is not unreasonable or unexpected. Thus, the time commitment for participating equals the time commitment for a high school course with homework. The time commitments are also reasonable considering two long weekends and a two-week Christmas break in the semester.

It is interesting to note that students taking a work experience or any semestered course can receive credits for completing a similar number of hours (6.7/week for 5 credits) that an athlete devotes to athletics. Students registered in career and technology studies (CTS) receive 1 credit for every 25 hours of coursework. At this rate, students participating in athletics would receive between 3 (for JV) and 5 (for varsity) credits.

There are several other factors to note in this study. First, the size of the school required the study to combine courses into disciplines. It would be of interest to expand the study and compare similar results by course.

Second, Magrath, as a small community, has a strong history of parental support and values that encourage academic and athletic success. This may not be present in other communities of similar or larger size. Third, high profile sports may vary from school to school. For example, at some schools football may be more important than volleyball or basketball. Fourth, a longitudinal study would highlight fluctuations during the year and indicate any long-term trends or patterns. Finally, it would be of interest to compare athlete performance during and after the season of competition. Would the desired benefits of standards continue after the sport was over?

Participation in athletics takes a considerable amount of dedication by athletes, especially to make choices regarding athletic, academic, and personal commitments. Athletes are matching or exceeding non-athletes' academic and behavioral performance while participating in a competitive level of athletics.

\section{Footnote}

NOTE: This study was made possible through a grant by the Alberta Advisory Committee for Educational Studies. 


\section{References}

American Sports Institute. Promoting Achievement in School Through Sport: Four-Year Impact Study and Summary Report Covering Data from 1991-92, 1992-93, 199394, and 1994-95 School Years. Mill Valley, Calif.: American Sports Institute, 1996. Carlson, T. "From Ivy League to NBA: A Great Urban High School Falls Through the Hoop." Policy Review, Spring 1993. Gerdy, J. R. "Faculty and Collegiate Athletics Reform: Seizing the Moment." Educational Record, Summer 1992.

Goldberg, A. D., and Chandler, T. J. L. "Academics and Athletics in the Social World of Junior High School Students." The School Counselor 40(1992): 40-45.

Harper, T. "Academic Eligibility Requirements for Student Athletes: Two Points of View." NASSP Bulletin, September 1986.

Haynes, L. L., III. "Athletics vs. Academics: A Focus on the Future." NASSP Bulletin, December 1990. Hood, A. B.; Craig, A. F.; and Ferguson, B. W. "The Impact of Athletics, Part-time Employment, and Other Activities on Academic Achievement." Journal of College Student Development 33(1992): 447-53.

Maloney, M. T., and McCormick, R. E. "An Examination of the Role That Intercollegiate Athletic Participation Plays in Academic Achievement." The Journal of Human Resources 3(1993): 555-70.

McMillen, T. "Reversing the Imbalance of Athletics and Academics." The Elementary School Journal 5(1991): 489-90.

Morton, S., et al. Academic Standards for Interscholastic Athletic Participation. Chapel Hill, N.C.: School of Education, The University of North Carolina, 1993.

Owings, J.; McMillen, Marilyn; and Daniel, Bruce. Who Can Play? An Examination of NCAA's Proposition 16. Statistics in Brief Washington, D.C.: National Center for Educational Statistics, 1995.

Rombokas, M., et al. "High School Extracurricular Activities and College Grades." Paper presented at the Southeastern Conference of Counseling Center Personnel and the Tennessee Counseling Association Convention, 1995.

Ruffin, S. C., Jr. "Minimum Academic Standards: Yes." NASSP Bulletin, September 1986. Scherer, J. "If Winning Isn't Everything-How Can It Be the Only Thing? NASSP Bulletin, December 1990. Soltz, D. F. "Athletics and Academic Achievement: What Is the Relationship?" NASSP Bulletin, September 1986.

Thompson, R. "Improving the Academic Performance of Athletes." NASSP Bulletin, September 1986. Whitner, P. A., and Myers, R. C. "Academics and an Athlete." Journal of Higher Education 6(1986): 659-72.

\section{AuthorAffiliation}

Holt Zaugg (zaugg@gmail.com) is a math teacher at the Magrath Junior/Senior High School in Magrath, Alberta, Canada.

Subject: Athletes; Secondary school students; Rural areas; Academic achievement; 
